\title{
BIBLIOGRAFÍA
}

\section{Hacia una Bibliografía de y sobre Juan Rulfo}

Esta bibliografía sobre la obra de Juan Rulfo pretende promover el estudio del ya famoso autor mexicano. Se reúnen aquí fichas sobre las obras mismas de Juan Rulfo y también comentarios críticos sobre ellas. Obviamente esta bibliografía no es completa pero representa el trabajo bibliográfico más extenso que se ha hecho sobre Juan Rulfo. Aunque hay bastantes excepciones, esta bibliografía se limita esencialmente a obras o trabajos en español o en inglés. Juan Rulfo mismo me ayudó bastante, principalmente en lo que se refiere a sus obras en traducción, sus obras cinemáticas, y algunas fichas sobre sus cuentos en traducción y estudios críticos sobre su obra.

Esta bibliografía se divide en seis partes para facilitar su uso:

I. Obras de Juan Rulfo: libros, cuentos, fragmentos, traducciones a otras lenguas extranjeras, antologías, y miscelánea.

II. Estudios bibliográficos.

III. Entrevistas y material biográfico.

IV. Referencias en general a la obra de Rulfo:

V. Reseñas y artículos sobre El llano en llamas.

VI. Reseñas y artículos sobre Pedro Páramo.

Con frecuencia se hace referencia a los suplementos literatios o culturales de varios periódicos publicados en México, D. F. Son los siguientes: La Cultura en México (CM) es el suplemento cultural de la tevista Siempre!; México en la Cultura (MC) es el suplemento cultural dominical del periódico Novedades; Diorama de la Cultura (DC) es el suplemento dominical del periódico Excelsior; Revista de la Semana (RS) es el suplemento cultural dominical del periódico El Universal; y El Gallo Ilustrado (GI) es el suplemento cultural dominical del periódico El Día. Asimismo se emplean las siguientes abreviaciones: JR por Juan Rulfo; 
LL por El llano en llamas, la colección de cuentos de Rulfo; y PP por Pedro Páramo, la novela de Rulfo.

La compilación de esta bibliografía se hizo posible por la ayuda de varias personas y bibliotecas. Especialmente quiero agradecer a Juan Rulfo, a Aurora Ocampo de Gómez, Directora Asistente del Centro de Estudios Literarios de la Universidad Nacional Autónoma de México, y a la Colección Latinoamericana de la Biblioteca de la Universidad de Texas en Austin.

Idabo State University

ARThur Ramírez

I. Obras de Juan Rulfo

\section{A. Libros y ediciones}

Se incluyen aquí la publicación original de los dos libros de JR y las ediciones que han salido después. Se apunta aquí la segunda edición de El llano en Illamas, "corregida y aumentada", publicada en 1970. También hay una edición escolar de El llano en llamas publicada en los Estados Unidos. Las otras referencias son una edición escolar de Pedro Páramo publicado en los Estados Unidos, una edición cubana que reúne las dos obras principales de Rulfo, una edición española que incluye, además de las dos obras principales, los dos otros cuentos y un fragmento que salieron después de la publicación de Pedro Páramo.

1. Rulfo, Juan. El llano en llamas. Primera edición. México: Fondo de Cultura Económica, 1953.

2. - El llano en llamas. Segunda edición corregida y aumentada. México: Fondo de Cultura Económica, 1970. (En esta edición se excluye "Paso del Norte", y se incluyen dos cuentos más: "El día del derrumbe" y "La herencia de Matilde Arcángel".)

3. - El llano en llamas. Edición preparada por Hugo Rodríguez Alcalá y Ray A. Verzasconi. Englewood Cliffs, New Jersey: Prentice-Hall, Inc., 1973.

4. —. Pedro Paramo. Primera edición. México: Fondo de Cultura Económica, 1955. 
5. - Pedro Páramo. Edición preparada por Luis Leal, con una "Introducción". New York: Appleton-Century-Crofts, 1970.

6. - Pedro Páramo y El llano en llamas y tres cuentos más ("El día del derrumbe", "La herencia de Matilde Arcángel", y "Un pedazo de noche"). Barcelona: Planeta, 1969.

7. - Pedro Páramo y El llano en llamas. Con una introducción por Antonio Benítez Rojo. Havana: Casa de las Américas, Colección Latinoamericana, 1968.

\section{B. Cuentos}

Se incluyen aquí los cuentos que Rulfo ha publicado en español en publicaciones hispánicas. Entre ellos se encuentran los cuentos que vendrían a formar El llano en llamas; la mayoría de ellos aparecieron originalmente en América pero uno salió en Pan. También se enumeran aquí los cuentos que Rulfo no incluyó en El llano en llamas y las republicaciones de sus cuentos. No se incluyen aquí referencias a los cuentos que han salido después en antologías. Esta información se encontrará en la subsección $G$.

8. Rulfo, Juan. "La cuesta de las comadres". América, Núm. 55 (29 de febrero, 1948), 31-38.

9. —. "La cuesta de las comadres". La Prensa (Lima), domingo, 12 de noviembre, 1961, 12-13.

10. ——. "El día del derrumbe". MC, No. 334 (14 de agosto, 1955), $3,5$.

11. _- "Díles que no me maten!" América, No. 66 (Agosto, 1951), 125-130.

12. —. "En la madrugada". Horizontes, VI, 34 (15 de diciembre, 1963), 30-32.

13. —_. "La herencia de Matilde Arcángel". CM (1969). (No hay más datos).

14. —. "La herencia de Matilde Arcángel". Humboldt (Revista para el mundo hispánico), 1963.

15 -. "Luvina". CM, Núm. 169 (12 de mayo, 1965), VI-VIII.

16. —. "El llano en llamas". América, Núm. 64 (dic., 1950), 66.85.

17. -. "Macario". América, Núm. 48 (junio, 1946), 67-72.

18. —. "No oyes ladrar los perros". Marcba (Montevideo), 2 de noviembre, 1955, 21. 
19. —. "No oyes ladrar los perros". MC, Núm. 695 (8 de julio, 1969), 9, 10.

20. —. "No oyes ladrar los perros". El campo en la prosa americana. (Un cuento mexicano). Anales (Sociedad Rural Argentina, Buenos Aires), 94, 8 (agosto, 1960), 586-588.

21. —. "Nos han dado la tierra". Pan (Guadalajara), 1945. (Esta revista literaria fue dirigida por Antonio Alatorre, Juan José Arreola y Juan Rulfo. No hay más datos.)

22. —-. "La presencia de Matilde Arcángel". Cuaderntos Médicos, I, 5 (1955), 57-61.

23. —- "La presencia de Matilde Arcángel". Metáfora, Núm. 4 (sept.oct., 1955), 27-32.

24. —. "Talpa". América, Núm. 62 (enero, 1950), 79-81.

25. —_. "La vida no es muy seria en sus cosas". América, 1942. (No hay más datos.)

\section{Fragmentos}

En esta subsección se encuentran tres fragmentos de novelas. El primero, "Un cuento", es un fragmento de Una estrella junto a la luna, que parece haber sido el primer título de PP porque en una versión revisada este fragmento forma el principio de PP. El segundo fragmento, "Los murmullos", se publicó originalmente como fragmentos de una novela titulada Los murmullos. Igual que en el caso del primer fragmento, éste llegó a formar parte de PP. "Un pedazo de noche", es el único fragmento publicado de la primera novela que escribió Rulfo. Rulfo ha dicho que esta novela, El bijo del desconsuelo, fue destruida por él.

26. Rulfo, Juan. "Un cuento". [Fragmento de la novela inédita, Una estrella junto a la lund.] Las Letras Patrias (México), Núm. 1 (enero-marzo de 1954), 104-108.

27. —. "Los murmullos". [Fragmento de la novela inédita, Los Murmullos.] Revista de la Universidad de México, VIII, 10 (junio, 1954), 6-7.

28. —. "Un pedazo de noche". Revista Mexicana de Literatura. Núm. 3 (septiembre, 1959), 7-14. 
D. Traducciones al inglés de cuentos y de un fragmento. (Se excluyen aquí los cuentos en traducción al inglés publicados en antologías. Estos se encuentran en la subsección G.)

29. Rulfo, Juan. "Anacleto Morones". Traducción de Anna West Chelsea Review, No. 6 (Winter, 1960), 47-59.

30. —_. "Because We're So Poor". Traducción de Henry Dyches. Mexico Quarterly Review (México), 1, 3 (Summer, 1962), 166-169.

31. —- "La herencia de Matilde Arcángel". Traducción de Margaret Schedd. Kenyon Review (1967).

32. —_. "The Hill of the Comadres". Traducción de Lysander Kemp. Atlantic, Vol. CCXIII (March, 1964), 102-105.

33. - "Luvina". Traducción de Joan y Boyd Carter. Mexican Life, XXXIV, 3 (March, 1958), 11-12, 64.

34. —_. "Luvina". Traducción de Joan y Boyd Carter. Prairie Schooner, XXXI, 4 (Winter, 1957-1958), 300-306.

35. - . "Macario", and "No Dogs Bark". Traducción de George D. Schade. The Texas Quarterly, II, 1 (Spring, 1959), 48-51; 52-55.

36. —_. "The Miraculous Child". Traducción de "Anacleto Morones" de Irene Nicholson. Encounter, V, 3 (Sept., 1955), 13-19.

37. — "The Night They Left Him Behind". Traducción de Robert Cleland. Mexican Life, XXXII, 11 (November, 1956), 17-18.

38. —. Pedro Páramo (fragmento). Traducción de Lysander Kemp. Evergreen Review, II, 7 (Winter, 1959), 45-58.

39. - Pedro Páramo (fragmento). Traducción de Lysander Kemp. Mexican Life, XXXIX, 6 (June, 1963), 11-12; 59-66.

40. - . "Talpa". Traducción de Robert Cleland. Mexican Life, XXXIII, 1 (Jan. 1957), 62, 64.

41. —_. "Tell Them Not to Kill Me". Traducción de Lysander Kemp. New World Writing, XIV (December, 1958), 116-122.

E. Traducciones a lenguas extranjeras de los libros de Rulfo

En esta subsección se encuentran seis traducciones de LL; quince de PP; y tres de las dos obras en un volumen. Además algunas traducciones de PP incluyen varios cuentos de LL. En total, LL ha sido traducida a nueve lenguas extranjeras y PP a 18. Esta enumeración no hubiera sido posible sin la ayuda de Rulfo mismo. 
Traducciones de El llano en llamas:

42. Rulfo, Juan. The Burning Plain and Other Stories. Traducción con introducción de George D. Schade. Austin: University of Texas Press, 1967.

43. - El llano en llamas. Traducción al polaco de Zofia Szleyen. (No hay más datos.)

44. - - Der Llano en Flammen. Traducción al alemán de Mariana Frenk. Munich: Carl Hanser Verlag, 1964.

45. —. La morte al Messico. Traducción al italiano de Giuseppe Cintioli. Milán: Atnoldo Mondadori, Editore, 1963.

46. —- La plaine en flammes. Traducción al francés de Michelle LeviProvençal. París: René Julliard, Edition Denoël, Las Lettres Nouvelles.

47. —. Planiny y plamenech. Traducción al checo. Praga: Dilia.

Traducciones de Pedro Páramo:

48. —. PP y varios cuentos de LL. Traducción al eslavonio de Alenka Bole-vralec. Liubliana, Yugoslavia: Sckankerjva. 1970.

49. — PP. Traducción al italiano. Milán: G. Feltrinelli. (No hay más datos.)

50. —_. PP. Traducción al sueco de Karin Alin. Estocolmo: Almqquist \& Wiksell/Gebors Förlag AB, 1960.

51. —. PP. Traducción al checo. (No hay más datos.)

52.—. PP. Traducción al portugués de Jurema Finamour. São Paulo: Editora Brasiliense, 1969.

53. —- PP. Traducción al finés. (No hay más datos.)

54. —. PP. Traducción al alemán de Mariana Frenk. Munich: Carl Hanser Verlag, 1958.

55. —. PP. Traducción al alemán de Mariana Frenk. Munich: Deutscher Taschenbuch Verlag. (En rústica.)

56. —- PP. Trađucción al húngaro. (No hay más datos.)

57. —. PP. Traducción al danés de Ib Jorgensen. Copenhague: Aschehoug Dansk Förlag, Levende Literatur, 1961.

58. —- PP: A Novel of Mexico. Traducción al inglés de Lysander Kemp. Nueva York: Grove Press, Inc., 1959.

59. —_. PP. Traducción al holandés de J. M. Leehner. Lochem: De Tijdstroom.

60. —. PP. Traducción al francés de Roger Lescot. París: Librairie Gallimard, Collection "La Croix du sud", 1959. (Esta edición 
incluye tres cuentos también: "La plaine en flammes", "Luvina", y "Anacleto Morones".)

61. - PP. Traducción al servocroata de Rodje Tatic. Belgrado: Nolit.

62. - PP. Traducción al polaco de Kalina Wojciechowska. Prólogo de Sergio Pitol. Varsovia: Ksiazka: Wiedza, 1966.

63. — PP. Traducción al noruego de Per Wollebaek. Oslo. J. W. Cappelens Förlag, 1961.

Traducciones de LL y PP en un volumen:

64. —. PP y LL. Traducción al ruso de P. Glazova. Prólogo, "El mundo de JR", de L. Ospovat. Moscú: L. P. House, 1970.

65. - - PP y LL. Traducción al rumano. (No hay más datos.)

66. —. PP y LL. Traducción al ucranio de Ivan Salyk. Llvov, Ucrania: Horotok.

F. Traducciones a otras lenguas extranjeras de cuentos en revistas:

En esta subsección se da una pequeña muestra de cuentos de Rulfo que han aparecido en revistas a periódicos en traducción a lenguas extranjeras además del inglés.

67. Rulfo, Juan. "¡Díles que no me maten!" Traducción al polaco de Zofia Szlegen. Przegleadn Kulturalnego. (Revista cultural de Varsovia), Dec. 14, 1961.

68. - - "Macario". Sonntagsbeilage, National-Zeitung Basel, No. 497, Sonntag, 27 oktober, 1968.

69. - (Cuento en alemán) $D u$, Zurich, Suiza.

70. —_. "Wallfahrt Nach Talpa". Traducción de Mariana Frenk de "Talpa". Introducción de Ricardo Cortés Tamayo. Blatter-Bilder (publicada por Andreas Lettner Verlag-Wurzburg-Wein), No. 6 (Feb., 1960), 23-33.

\section{G. Antologías}

Esta subsección se dedica a cuentos publicados en antologías, en el español original o en lenguas extranjeras. Una cantidad notable de las antologías en español se han publicado en los Estados Unidos, destinadas 
para estudiantes universitarios norteamericanos, muy a menudo con introducciones y notas en inglés.

Antologías en español

72. Rulfo, Juan. "La cuesta de las comadres", pp. 658-664. En Historia $y$ antología del cuento y la novela en Hispanoamérica, Angel Flores, ed. Nueva York: Las Américas Publishing Co., 1959.

73. - "El día del derrumbe", pp. 191-201. En Anuario del cuento mexicano: 1955. México: Instituto Nacional de Bellas Artes, 1956.

74. - - "El día del derrumbe", pp. 13-24. En Crónicas de Latinoamérica, Prólogo, "América Latina: de la tradición a la conquista", pp. 7-12, y notas de Ricardo Piglia. Buenos Aires: Editorial Jorge Alvarez, 1968.

75. ㄴ. "¿Diles que no me maten!", pp. 627-633; "Luvina”, pp. 633-641; "No oyes ladrar los perros", pp. 641-644; y "Anacleto Morones", pp. 645-656. En El cuento mexicano del siglo $X X$ (Antología), Emmanuel Carballo, ed. México: Empresas Editoriales, 1964.

76. - “- ¡Diles que no me maten!", pp. 155-162. En Antología del cuento mexicano, Luis Leal, ed. México: Ediciones de Andrea, 1957.

77. —. " „Díles que no me maten!”, pp. 52-60. En Diez cuentos mexicanos contemporáneos, Joffre de la Fontaine, ed. Xalapa, Veracruz: Universidad Veracruzana, 1967.

78. —_ "Diles que no me maten!", pp. 34-41. En Seven Stories from Spanish America, Gordon Brotherston y Mario Vargas Llosa, eds. New York: Pergamon Press, 1968.

79. - "En la madrugada", pp. 94-98. En Cuentistas bispanoamericanos del siglo veinte, Luis Leal, ed. New York: Random House, 1972.

80. —_. "Es que somos muy pobres", pp. 121-126; "El hombre", pp. 127-136; "¿Díles que no me maten!", pp. 138-145; "Luvina", pp. 147-156; y "No oyes ladrar los perros", pp. 158-163. En Cinco maestros: Cuentos Modernos de Hispanoamérica, Alexander Coleman, ed. New York: Harcourt, Brace \& World, Inc., 1969.

81. —. "La herencia de Matilde Arcángel", pp. 218-223. En Anuario del cuento mexicano: 1959. México: Instituto Nacional de Bellas Artes, 1960.

82. ㄴ. "El hombre", pp. 3-13. En Cuentistas mexicanos modernos, 
Vol. I, Emmanuel Carballo, ed. México: Ediciones Libro-Mex., 1956.

83. —_. "Luvina". Antología del cuento fantástico, Roger Caillois, ed. Buenos Aires: Sudamericana, 1967.

84. —- "Luvina", pp. 29-38. En Antología del realismo mágico: ocho cuentos bispanoamericanos, E. Dale Carter, Jr., ed. New York: The Odyssey Press, 1970.

85. —_. "Luvina", pp. 95-103; "Paso del norte", pp. 103-110; "No oyes ladrar los perros", pp. 110-114. En Novelistas contemporáneos bispanodmericanos, Fernando Alegria, ed. Boston: D. C. Heath \& Co., 1964.

86. —_. "Macario", pp. 11-17; " ¿Díles que no me maten!", pp. 18-27;

"Anacleto Morones", pp. 28-45. En 30 cuentos de autores mexicanos jóvenes, Héctor Gally C., ed. México: Editorial Pax-México, 1967.

87. ——. "Nos han dado la tierra", pp. 156-160. En 33 cuentos mexicanos. 2a. Edición. Seleccionados por Felipe Sánchez Murguía. México, 1964.

88. - - "No oyes ladrar los perros", pp. 79-83. En Curso intermedio de español, por David. L. Wolfe. New York: The MacMillan Co., 1972.

89. ——. "Pedro Páramo" (fragmento), pp. 159-163. En Antología de becarios (1951-1966) del Centro Mexicano de Escritores. México, 1968.

90. - - (Cuentos). Llano grande: Antología de la literatura mexicana. (Antología alemana con cuentos en español.) Berlín, 1964.

91. —- "Talpa", pp. 168-187. Texto bilingüe -en español y en inglés. Versión en inglés de J. A. Chapman. En Short Stories in Spanish. Cuentos bispánicos, Jean Franco, ed. Baltimore: Penguin Books, 1966.

92. - . "Talpa", pp. 232-240. En Voces hispanoamericanas, Peter G. Earle, ed. New York: Harcourt, Brace \& World, Inc., 1966.

93. —- "Talpa", pp. 105-114. En Antologia contemporáned del cuento mexicano, Enrique Congrains Martín, ed. México: Instituto Latino-Americano de Vinculación Cultural, 1963.

94. - - "Un cuento", pp. 441-446. En Anuario del cuento mexicano: 1954. México: Instituto Nacional de Bellas Artes, 1955. 
Antologías en lenguas extranjeras:

95. —. "Because We Are So Poor", pp. 300-304. Traducción al inglés de Lysander Kemp. En Great Spanish Short Stories, Angel Flores, ed. New York: Dell Publishing Co., Inc., 1962.

96. - . 'The Day of the Landslide", pp. 223-229. En Doors and Mirrors: Fiction and Poetry from Spanish America 1920-1970, Hortence Carpentier y Janet Brof, eds. New York: Grossman Publishers, 1972.

97. - _ . "En la madrugada", pp. 28-33. Traducción al holandés de J. M. Lechner. En Kronick van Kurst en Kuldur.

98. —_. "Luvina". En Antologie du Fantastique, Roger Caillois, ed. París: Club Français du Libre, 1958.

99. - - "Luvina". Traducción al alemán. En Excursionen (Erzahlungen unserer Zeit), Leone Germann, ed. Munich: Carl Hanser, 1964.

100. - - "Luvina". Traducción al alemán. En Moderne Erzäbler ans West un Ost. Munich: Wilhelm Goldman Verlag, 1964.

101. _-. "Macario", pp. 48-51; y "No Dogs Bark", pp. 52.55. Traducción aI inglés de George D. Schade. En The Muse in Mexico, Thomas Cranfill, ed. Austin: The University of Texas Press, 1959.

102. - (Cuento). Antología de literatura latinoamericana en alemán. Traducción y notas de G. Menz. Frankfort: Necyo, 1966.

103. ——. "Talpa", pp. 168-187. Texto bilingüe —versión en inglés de J. A. Chapman. En Short Stories in Spanish. Cuentos hispanicos, Jean Franco, ed. Baltimore: Penguin Books, 1966.

104. __. "They Gave Us the Land", pp. 174-178. Traducción al inglés de Jean Franco. En Latin American Writing Today. J. M. Cohen, ed. Baltimore: Penguin Books, 1967.

\section{H. Miscelánea}

Se incluyen aqui algunas de las películas en que ha colaborado Rulfo, con sus comentarios sobre ellas; una obra histórica de Rulfo; y un disco.

105. Rulfo, Juan. El despojo. (Rulfo escribió el cinedrama de esta película que dura 30 minutos. Según Rulfo, fue filmada en El Mesquital y trata de "un cacique que le quita todo a un joven músico - le quita la mujer, etc.") 
106. - La fórmula secreta, Cinedrama, en tres escenas, 1967, con dirección y camarografía de Rubén Gámez. (Según Rulfo, esta película ganó el primer premio en el concurso Cine Experimental de México. Esta película se tituló originalmente "Coca Cola en la sangre". Según Rulfo, es superrealista, "una cinta al revés, llena de flasbbacks y de reflejos luminosos y la oscuridad".)

107. - El gallo de oro. Guión cinematográfico, 1964. (Cinedrama de Carlos Fuentes y Gabriel García Márquez. Según Rulfo, se hicieron muchos cambios en su guión.)

108. - Maya. Narración de Rulfo, una paráfrasis del Popul Vub y del Chilam Mayan, dirección de Jacque Spurrier y camarografía de Rubén Gámez. (Según Rulfo, esta película pretende presentar "todo el mundo de los mayas, incluyendo ceremonias del Día de los Muertos, brujeria, hechicería y ruinas mayas". Rulfo añadió que algunas de las escenas que él escribió no se filmaron.)

109. - - ed. Noticias históricas de la vida y bechos de Niño de Guzmân. Selección y "Prólogo", pp. XI-XV, de Juan Rulfo. Vol. I de Libros y documentos para la bistoria de la Nueva Galicia. Guadalajara, Jalisco: Círculo Occidental, 1962.

110. —. "Juan Rulfo". Lectura de JR de dos de sus cuentos, "Luvina" y " "Díles que no me maten!" en un disco de la serie Voz Viva de México. "Presentación" de Carlos Blanco Aguinaga. México: Universidad Nacional Autónoma de México, 1963.

II. Estudios bibliográficos

111. Leal, Luis. Bibliografía del cuento mexicano. México: Ediciones de Andrea, 1958. (JR: p. 131.)

112. Ocampo, Aurora Maura. Literatura mexicana contemporánea, bibliografía crítica. México: Tesis, Facultad de Filosofía y Letras, Universidad Nacional Autónoma de México, 1965.

113. Ocampo de Gómez, Aurora Maura, y Ernesto Prado Velázquez. Diccionario de escritores mexicanos. Panorama de la Literatura Mexicana por María del Carmen Millán. México: Universidad Nacional Autónoma de México, Centro de Estudios Literarios, 1967. (JR: pp. 346-347.) 
III. Entrevistas y material biográfico

114. Anon. "Cien mil ejemplares de las obras de Juan Rulfo en Ruso", Excelsior, jueves, 22 de octubre, 1970, p. 28-A.

115. - "Díaz Ordaz entregó Premios Nacionales". Avance, jueves, 26 de noviembre, 1970, pp. 1.4 (supl.).

116. - - "Empeño del Presidente en satisfacer la creciente demanda de cultura". El Universal, jueves, 26 de noviembre, 1970, pp. 1, 15.

117. —. "Entregó el Presidente D. O. [sic], los Premios de Ciencias, Letras y Arte". Excelsior, jueves, 26 de noviembre, 1970, pp. 31-A, 32-A.

118. - - "Graef Fernández, Rulfo y González Camarena enriquecen el grupo de mexicanos eminentes". El Nacional, jueves 26 de noviembre, 1970 , p. 1.

119. - J. R. Pp. 23-26. En Los narradores ante el público. México: Joaquín Mortiz, 1966.

120. —. "¿Una res pública o una pura nada? ¡El de 'Comala' recibió su premio!" "JR concede -ipor fin!-_- una entrevista exclusiva y a nosotros". Revista de la Semana, 6 de diciembre, 1970, pp. 10-11.

121. - "Textos de JR, hoy, en Chapultepec". Excelsior, domingo, 8 de noviembre, 1970 , p. 7-D.

122. Bambi. " 'La Cordillera', nuevo libro de JR". Excelsior, martes, 16 de abril, 1963, pp. 4-A, 5-A.

123. Cervera, Juan. "Entrevista a JR". El Mundo (La Habana), Suplemento Cultural, 25 de enero, 1969.

124. —. "Entrevista con JR". La Gacela, XV, 8 (oct. 1968), 7-11.

125. Cortés Tamayo, Ricardo. "JR". DC, 31 de mayo, 1959, p. 4.

126. Ealling, Till. [Nota sobre JR, introducción al cuento "La cuesta de las comadres" de JR.] América, Núm. 55 (29 de feb., 1948), 31-32.

127. Ferro, Helén. "La nueva novela mexicana: Visión de JR". Américas, XVI (noviembre, 1964), 40-41.

128. Flores, Angel. "JR", pp. 657-658. En su Historia y antología del cuento y la novela en Hispanodmérica. New York: Las Américas Publishing Co., 1959.

129. Gómez Gleason, María Teresa. "JR y el mundo de su próxima novela 'La cordillera' ", CM, Núm. 228 (29 de junio, 1966), VI.

130. González Machado, Ricardo. "JR, a quien atrae la vida del campe- 
sino, recibió el Premio Nacional de Letras". El Nacional, jueves, 26 de noviembre, 1970, p. 6.

131. González Pagés, Andrés. "'El ambiente intelectual es el más difícil, el más escabroso" ". [Entrevista a JR.] El Día, 14 de abril, 1964, p. 9.

132. Guillén, Fedro. "Posición de Rulfo y Pellicer", respecto a la intervención yanki en la Dominicana. Siempre!, Núm. 621 (19 de mayo, 1965), 56.

133. Harss, Luis. "JR, o la pena sin nombre", pp. 301-337. En su Los nuestros. Buenos Aires: Editorial Sudamericana, 1966.

134. Harss, Luis, and Barbara Dohmann. "JR, or the Souls of the Departed", Chapter VII, pp. 246-275. En su Into the Mainstream: Conversations with Latin-American Writers. New York: Harper \& Row, 1967.

135. Landeros, Carlos. "Charla con JR". DC, 6 de marzo, 1966, pp. 3, 6.

136. Lidio, Dimas. "Rulfo". [Entrevista] GI, Núm. 419 (5 de julio, 1970), 3.

137. [M.A.M.] [Nota sobre JR, introducción al cuento "Macario" de JR.] América, Nủm. 48 (junio, 1946), 67.

138. Melgoza, Arturo. "Algunos juicios de Rulfo", pp. 40-44. En Recopilación de textos sobre Juan Rulfo. Serie Valoración Múltiple. La Habana: Casa de las Américas, Centro de Investigaciones Literarias, 1969.

139. Mendoza, María Luisa. "Frustrado de la literatura". DC, domingo, 25 de noviembre, 1956, pp. 2, 3.

140. —. "La O por lo redondo". El Dia, 17 de enero, 1966, p. 2.

141. Mora, Gustavo. "Reconocen la preocupación de GDO' [sic] por exaltar los valores culturales". Novedades, jueves, 26 de noviembre, 1970, pp. 1, 9.

142. Ochoa, Guillermo. "No tengo obligación de escribir', dice Rulfo". Excelsior, domingo, 2 de marzo, 1969, pp. 1-A, 10-A.

143. Pacheco, José Emilio. "Imagen de JR". MC, Núm. 540 (19 de julio, 1959), 3.

144. Poniatowska, Elena. "Charlando con JR". Excelsior, viernes, 15 de enero, 1954, pp. 1-B, 7-B.

145. - - "Montes de Oca y JR". MC, Núm. 509 (14 de diciembre, 1958), 2, 10.

146. - JR, pp. 306-307. En Palabras cruzadas. México: Era, 1961.

147. —. "Perfiles literarios: Juan Rulfo", Pp. 45-46. En Recopilación 
de textos sobre Juan Rulfo. Serie Valoración Múltiple. La Habana: Casa de las Américas, Centro de Investigaciones Literarias, 1969. 148. Restrepo Fernández, Iván. "La caceria de JR". Mundo Nuevo, Núms. 39-40 (Sept.-Oct., 1969), 43-44.

149. Rodríguez, J. M. "La inversión intelectual es tanto o más importante para el país que la económica". El Día, jueves, 26 de noviembre, 1970, p. 1.

150. Rojas Zea, Rodolfo. "México en las Ciencias, la Pintura y las Letras, según los Premios". Excelsior, domingo, 22 de noviembre, pp. 1-A, 18-A.

151. —- "Rulfo analiza al escritor iberoamericano". Excelsior, jueves, 4 de marzo, 1971, pp. 1-A, 12-A.

152. Rulfo, Juan. Discurso al recibir el Premio Nacional de Letras 1970. El Día, jueves, 26 de noviembre, 1970, p. 10.

IV. Referencias en general a la obra de Rulfo:

En esta sección se encuentran fichas sobre la obra de Rulfo en un contexto amplio, el de la literatura latinoamericana, hispanoamericana, o mexicana. También se incluyen referencias generales a la obra de Rulfo, tanto a sus cuentos como a su novela.

153. Acevedo Escobedo, Antonio. "En torno a Rulfo". El Nacional, 6 de marzo, 1966, p. 3.

154. Acker, Bertie Wilcox Naylor. "Themes and World View in the Contemporary Mexican Short Story: Rulfo, Arreola and Fuentes". Austin: The University of Texas, tesis doctoral inédita, 1971.

155. Alegría, Fernando. JR y PP, Pp. 257-259. En su Historia de la novela bispanoamericana. 3a. edición. México: Ediciones de Andrea, 1966.

156. - JR, p. 59. En La novela hispanoamericana del siglo XX. Buenos Aires: Centro Editor de América Latina, 1967.

157. —-, ed. "Introducción", pp. 1-7, y JR, p. 94. En Novelistas contemporáneos hispanoamericanos. Vocabulario y notas por Carlos Lozano. Boston: D. C. Heath, 1964.

158. Algaba Martínez, Leticia. "Notas sobre la novela mexicana en los últimos quince años". Armas y Letras, Segunda Epoca, 1-2 (enerojunio, 1962), 5-24. 
159. Alvarez, Federico. "1953/63: La novela mexicana". CM, Núm. 72 (3 de julio, 1963), XIII-XV.

160. Amorós, Andrés. JR, pp. 137-140. En Introducción a la novela bispanodmericana actual. Madrid: Ediciones Anaya, 1971.

161. Anderson Imbert, Enrique. "Formas en la novela contemporánea", pp. 261-269. En su Critica interna. Madrid: Taurus, 1961.

162. - J JR, pp. 330-331. En Historia de la literatura bispanoamericana. Vol. II, Epoca contemporánea. México: Fondo de Cultura Económica, cuarta edición, 1964.

163. - - JR, pp. 254-255. En Historid de la literatura bispanoamericana. Vol. II. México: Fondo de Cultura Económica, 1966.

164. —. "La novela en América Latina", Cuadernos (París), No. 89 (Oct., 1964), 7-13.

165. - JR, p. 536. En Spanish American Literature; A History. Traducción de John V. Falconieri. Detroit: Wayne State University Press, 1963.

166. Anon. "Cinco grandes cuentistas". Tiempo, 7 de sept., 1964, p. 98.

167. —- "Fifteen Young Mexican Writers". Recent Books in Mexico (Bulletin of the Centro Mexicano de Escritores), III, 3 (March 15, 1957), 1, 2, 6, 7.

168. - - "Notas para un panorama de la novela en América Latina". Revista Nacional de Cultura, XXIX, 180 (1967), 76-113.

169. —. Nota sobre "Las ánimas", ballet inspirado por PP. Cuadernos de Bellas Artes, Núm. 4 (nov., 1960), 71.

170. —_. "La obra de Juan Rulfo". RS, 6 de diciembre, 1970, pp. 8-9.

171. —_. "Prose and Poetry in Spanish America: The Move Away from European Styles and Themes". The Times Literary Supplement (London), No. 2788 (Friday, August 5, 1955), xlviii.

172. Arciniegas, Germán. "JR en Bogotá". El Tiempo, 15 de dic., 1966, p. 5.

173. Arenas, Reinaldo. "El páramo en llamas". El Mundo (La Habana), 7 de julio, 1968.

174. ——. "El páramo en llamas", pp. 60-63. En Recopilación de textos sobre Juan Rulfo. Serie Valoración Múltiple. La Habana: Casa de las Américas, Centro de Investigaciones Literarias, 1969.

175. Argüedas, José Maria. "Primer diario", pp. 11-31, "Testimonio y. meditaciones sobre la gente y sobre el Perú", incluye referencias a JR. En su novela El zorro de arriba y el zorro de abajo. Buenos Aires: Editorial Losada, 1971. 
176. —- "Reflexiones peruanas sobre un narrador mexicano". El Comercio, suplemento dominical (Lima, Perú), 8 de mayo, 1960, p. 3.

177. Armand, Octavio. "Sobre las comparaciones de Rulfo". Nueva Narrativa Hispanoamericana, II, 2 (septiembre, 1972), 173-177.

178. Arreola, Juan José y Emmanuel Carballo. "Rulfo ha dado los más grandes palos de ciego de nuestra literatura". CM, Núm. 187 (15 de sept., 1965), XIII-XIV.

179. Arrom, José Juan. JR, pp. 205-206. En Esquema generacional de las letras bispanoamericanas: Ensayo de un método. Bogotá: Instituto Caro y Cuervo, 1963.

180. Aub, Max. Guía de narradores de la Revolución Mexicana. México: Fondo de Cultura Económica, 1969. (JR, pp. 58-62).

181. Augier, Angel. "Polémica de la novela". Unión (Revista de la Unión de Escritores y Artistas de Cuba), VI, 2 (junio, 1968), 139-146.

182. Baker, Armand F. "El tiempo en la novela hispanoamericana". Iowa City, Iowa: tesis doctoral inédita, University of Iowa, 1968.

183. Benedetti, Mario. "JR y las posibilidades del criollismo". Marcha, 2 de nov., 1955, pp. 20-23.

184. —- "JR y su purgatorio a ras del suelo". En Letras del continente mestiza. Montevideo: Arca, 1967.

185. Benítez Rojo, Antonio. "Juan Rulfo y su época", pp. 283-284. Prólogo a $L L$ y PP. La Habana: Casa de las Américas, 1968.

186. —_. "Rulfo duerme y vela", pp. 64-71. En Recopilación de textos sobre Juan Rulfo. Serie Valoración Múltiple. La Habana: Casa de las Américas, Centro de Investigaciones Literarias, 1969.

187. Blanco Aguinaga, Carlos. "Presentación", pp. 1-2. En un disco, "JR", en el cual el autor lee dos de sus cuentos, "Luvina" y "¡Díles que no me maten!" En la serie Voz Viva de México. México: Universidad Nacional Autónoma de México, 1963.

188. —. "Realidad y estilo de JR". Revista Mexicana de Literatura, I, 1 (sept.-oct., 1955), 59-86.

189. - - "Realidad y estilo de JR", pp. 85-113. En Nueva Novela Latinoamericana, compilación de Jorge Lafforgue. Buenos Aires: Editorial Paidós, 1969.

190. Brushwood, John S. Mexico in Its Novel: A Nation's Search for Identity. Austin: University of Texas Press, 1966. (JR, Pp. 30-34.)

191. — y José Rojas Garcidueñas. Breve bistoria de la novela mexicana. México: Ediciones de Andrea, 1959 (JR, pp. 140-141.) 
192. Caballero Calderón, Eduardo. "La novela y la soledad", Cuadernos (París), No. 70 (March, 1963), 26-28.

193. Camacho Guizado, Eduardo. "Notas sobre la nueva novela hispanoamericana". Nueva Narrativa Hispanoamericana, I, 1 (enero de 1971), 133-135.

194. Cambours Ocampo, Arturo. El problema de las generaciones literarias Buenos Aires, 1963.

195. Campos, Julieta. "El mundo absorto de JR", pp. 167-171. En su La imagen en el espejo. México: UNAM, Col. Poemas y Ensayos, 1965.

196. —- "La novela mexicana después de 1940", pp. 141-157. En su La imagen en el espejo. México: Universidad Nacional Autónoma de México, 1965. (JR, PP, pp. 151-152.)

197. —- "¿Realismo mágico o realismo crítico?" Revista de la Universidad de México, XV, 5 (enero, 1961), 4-8. (JR, PP, p. 6.)

198. Carballo, Emmanuel. "Arreola y Rulfo cuentistas". Universidad de México, VIII (marzo, 1954), 28-29, 32.

199. - - "Cuentistas jóvenes de México". Revista de la Universidad de México, XI, 4 (diciembre de 1956), 4.

200. - Cuentistas mexicanos modernos. México: Ediciones LibroMex., 1956. (JR, Vol. I, pp. VI-XVI.)

201. - El cuento mexicano del siglo XX (Antología). México: Empresas Editoriales, 1964. (JR, pp. 60-70.)

202. —. "Del costumbrismo al realismo crítico". Casa de las Américas, III, 19 (1963), 3-19.

203. —- "Los diez mejores cuentos mexicanos del siglo $\mathrm{xx}$ según Luis Leal". MC, Núm. 598 (agosto 28, 1960), 4.

204. ——. "Historia sexenal del cuento mexicano". CM, Núm. 169 (12 de mayo, 1965), II-III.

205. —_. "JR, Gran Prosista y Poeta: Premio Nacional de Letras". Excelsior, jueves, 26 de noviembre, 1970, pp. 7-A, 12-A.

206. - - "Las letras mexicanas de 1949 a 1954". Ideas de México, V, 2 (sep.-dic., 1954), 3-12.

207. - "Mi pequeña constelación jalisciense". Universidad de México, XI (enero, 1957), 4.

208. —. "La narrativa mexicana de hoy". Sur, Núm. 320 (1969), 2-14.

209. - "Notas sobre Rulfo, Arreola, Fuentes y el cuento mexicano de nuestros dias". MC, Núm. 634 (8 de mayo, 1961), 2.

210. —_ "La prosa narrativa en México". Casa de las Américas, V, 28 (1965), 3-17. 
211. Castellanos, Rosario. "La novela mexicana contemporánea", pp. 83113. En su Juicios sumarios. Xalapa, Veracruz: Universidad Veracruzana, 1966. (JR y PP, pp. 97-99.)

212. - "La novela mexicana contemporánea". MC, Núm. 597 (agosto 22,1960$), 1,5,10$.

213. - . "La novela mexicana contemporánea y su valor testimonial". Hispania, XLVII (May, 1964), 223-230.

214. - - "Tendencias de la novelística mexicana contemporánea". Universidad de Méxica, marzo, 1966.

215. Castagnino, Raúl. "Algunas cuestiones de sociologia literaria frente a la Nueva Novela Hispanoamericana". Nueva Narrativa Hispanoamericana, II, 2 (Septiembre de 1972), 33-44.

216. - - "Algunos rasgos comunes en la novela hispanoamericana actual", pp. 351-360. En La novel iberodmericana contemporánea: XIII Congreso Internacional de Literatura Iberoamericana. Segunda Reunión, 2 al 13 de agosto de 1968. Caracas, Venezuela: Ediciones de OBE (Organización de Bienestar Estudiantil), Universidad Central de Venezuela, 1968.

217. Castro, Rosa. "La responsabilidad del escritor: Una entrevista con Ali Chumacero". MC, 21 de feb., 1954, p. 3.

218. Chávarri, Raúl. "La novela moderna mexicana". Cuadernos Hispanoamericanos, LVIII, 173 (Mayo, 1964), 367-379. (JR, pp. 375-376.)

219. - "El personaje en la moderna novela mexicana". Cuadernos Hispanoamericanos, Núm. 215 (1967), 395-400.

220. Chumacero, Alí. "Las letras mexicanas en 1953". Las Letras Patrias, Núm. 1 (enero-marzo, 1954), 117-118.

221. - "Las letras mexicanas en 1955". Universidad de México, X (febrero, 1956), 25-29, 32. (JR, p. 26.)

222. —_. "Rulfo, Pozas, Valadés: tres aspectos de la vida mexicana". MC, Núm. 559 (29 de noviembre, 1959), 12, 5.

223. Coddou, Marcelo. "Del cuento naturalista al superrealista en Hispanoamética". Nueva Narrativa Hispanoamericana, II, 1 (enero de 1972), 196-198.

224. - Reseña de $E l$ arte de $J R$ de Hugo Rodríguez Alcalá. Anales de la Universidad de Chile, Núm. 137 (enero-marzo, 1966).

225. Cohen, J. M. "Tendencias indias y europeas en la literatura reciente mexicana". La Gaceta del Fondo de Cultura Económica. II, 8 (15 de abril, 1955), 3.

226. Coleman, Alexander. "Juan Rulfo", pp. 117-119. En su Cinco 
maestros: Cuentos modernos de Hispanodmérica. New York: Harcourt, Brace \& World, Inc., 1969.

227. Colina, José de la. "Notas sobre JR". Casa de las Américas, IV, 26 (oct.-nov., 1964), 133-138.

228. Colina, José de la. "Novelistas mexicanos contemporáneos". La palabra y el Hombre (oct.-dic., 1959), 574.589.

229. Couffon, Claude. "Carlos Fuentes y la novela mexicana". Cuadernos (del Congreso por la Libertad de la Cultura), No. 42 (mayojunio, 1960), 67-69.

230. Coulthard, Gabriel R. "Spanish American Novel: 1940-1965". Caribbean Quarterly, 12, 4 (1967), 3-29.

231. Courtney, Winifred F. "JR", p. 822. En The Reader's Adviser: $A$ Guide to the Best in Literature. 11th edition, revised and enlarged. New York: R. R. Bowker Co., 1968.

232. Cruz Castelán, Charlotte Abbott. "Vista general idel cuento-corto contemporáneo de México y de los Estados Unidos de Norteamérica". México, D. F.: Tesis, Universidad Nacional Autónoma de México, Escuela de Verano, abril de 1956.

233. Cuza Malé, Belkis. "JR, realismo por medio". Unión, IV, 2 (abriljunio, 1965), 165-166.

234. Díaz Seija, Pedro. 'De Agustín Yáñez a Juan Rulfo". Imagen (Quincenario de Arte, Literatura e Información Cultural, Caracas, Venezuela), Núm. 76 (julio 1-15, 1970), 3-5.

235. - - "Una ojeada a la novelística hispanoamericana en cinco dimensiones", pP. 59-68, JR y PP, p. 62. En La novela iberoamericana contemporánea: XIII Congreso Internacional de Literatura Iberoamericana. Segunda Reunión, 2 al 13 de agosto de 1968. Caracas, Venezuela: Ediciones de OBE (Organización de Bienestar Estudiantil, Universidad Central de Venezuela), 1968.

236. Diez, Luis A. "Tras La cordillera perdida de JR". El Norte de Castilla (Sevilla), domingo, 16 de agosto, 1970, p. 13.

237. Donoso Pareja, Miguel. "Arreola, Rulfo, De la Cuadra, Palacio, cuatro escritores de América". Ovaciones, supl. Núm. 132 (5 de julio, 1964), 8.

238. Durán, Manuel. "JR: la máscara y la voz". Insula (Madrid), XXV, 284-285 (julio-agosto, 1970), 18-19.

239. Dyches, Henry Perry. "JR: una tradición y un principio". México: Tesis, Universidad Nacional Autónoma de México, Facultad de Filosofía y Letras, 1964.

240. Earle, Peter G. "Camino oscuro: la novela hispanoamericana con- 
temporánea". Cuadernos Americanos, Año XXVI, Vol. CLII (mayo-junio, 1967), 204-222. (JR y PP, Pp. 213-215.)

241. ——. "JR", pp. 230-231. En su Voces bispanoamericantis. New York: Harcourt, Brace \& World, Inc., 1966.

242. Englekirk, John E. "Mexican Literature Today: 1950-1963", pp. 152-168. En The Caribbeant: Mexico Today, A. Curtis Wilgus, ed. Gainesville, Florida: University of Florida Press, 1964.

243. Esquenazi-Mayo, Roberto. "Marginal Notes on the Twentieth-Century Spanish American Novel". Prairie Schooner, 39 (1964), 126131.

244. Fernández, Sergio. "El llano en llamas de Juan Rulfo", pp. 113-141. En su Cinco escritores bispanoamericanos. México: Facultad de Filosofía y Letras, Núm. 30, Eds. Filosofía y Letras, UNAM, 1958. 245. Flores, Angel. "Los cuentos de hoy". Américas, VIII, Núm. 1 (enero, 1956), 36-37.

246. —- "Introduction", pp. 7-12, 300. En Great Spanish Stories, Angel Flores, ed. New York: Dell, 1962.

247. - "JR", pp. 657-658. En su Historia y antologia del cuento y la novela bispanoamericana. New York: Las Américas Publishing Co., 1959.

248. —_. "Magical Realism in Spanish American Fiction". Hispania, XXXVIII (May, 1955), 187-193.

249. Fontaine, Joffre de la. Nota de presentación, selección y vocabulario. Diez cuentos mexicanos contemporáneos. Xalapa, Veracruz: Universidad Veracruzana, 1967.

250. Fornet, Ambrosio. "La nueva narrativa y sus antecedentes". Casa de las Américas, IV, 22 (1964), 3-10.

251. Franco, Jean. JR, pp. 348-350. En An Introduction to Spanish American Literature. Cambridge: Cambridge University Press, 1969.

252. - JR, pp. 243-244 y p. 302. En The Modern Culture of Latin America: Society and the Artist. Revised Edition. Bungay, Suffolk: Pelican Books, 1970.

253. Fressard, Jacques. "Cultura americana en Europa". Excelsior, domingo, 22 de enero de 1967, p. 6.

254. Fuentes, Carlos. JR, pp. 15-16. En La nueva novelat bispanoamericana. México: Cuadernos de Joaquín Mortiz, 1969.

255. - - "La nueva novela latinoamericana". CM, Núm. 128 (29 de julio, 1964), 2-5.

256. Galaos, José Antonio. "Hispanoamérica a través de sus novelas". Cuadernos Hispanoamericanos, Núm. 143 (1961), 241-249. 
257. Gally C., Héctor. Prefacio, pp. 5-7, recopilación y notas. 30 cuentos de autores mexicanos jóvenes. México: Editorial Pax-México, 1967.

258. Gertel, Zunilda. JR y PP, pp. 108-114. En La novela bispanoamericana contemporanea. Buenos Aires: Nuevos Esquemas, 1970.

259. Giordano, Jaime. "Hacia una definición del realismo en la novela hispanoamericana contemporánea". Nueva Narrativa Hispanoamericana, I, 1 (enero de 1971), 127-132.

260. Gleaves, Robert M. 'Los pasos perdidos, PP, and the 'Classic' Novel in Spanish America". Language Quarterly, 8, i-ii (1969), 5-8.

261. Goic, Cedomil. "Estructura de la novela hispanoamericana contemporánea", pp. 43-53. En La naturaleza y el bombre en la novela bispanoamericana. Primer Seminario Internacional de Literatura Hispanoamericana. Autofagasta, Chile: Universidad del Norte, 1969.

262. Gómez-Gil, Orlando. Historia crítica de la literatura hispanoamericona: Desde los origenes basta el momento actual. New York: Holt, Rinehart \& Winston, 1968. (JR, Pp. 722-724.)

263. González, Manuel Pedro. "La novela hispanoamericana en el contexto de la internacional", pp. 35-109. En Coloquio sobre la novela bispanoamericana. México: 'Tezontle, Fondo de Cultura Económica, 1967. (JR, pp. 63-64.)

264. González Casanova, Enrique. "La actividad cultural en México: análisis general". El Día, 26 de junio, 1962, p. 5.

265. - . "Un cuento de nunca acabar: los cuentistas". CM, Núm. 74 (17 de julio, 1963), XVI-XVIII.

266. González Pena, Catlos. Historia de la literatura mexicana. Desde los orígenes hásta nuestros días. Décima Edición. Con un apéndice elaborado por el Centro de Estudios Literarios de la Universidad Nacional Autónoma de México. México: Editorial Porrúa, "Sepan Cuantos. ..", Núm. 44, 1969. (JR, p. 318.)

267. - History of Mexican Literature. Traducción de Gusta Barfield Nance y Florene Johnson Dunstan. Third edition. Dallas: Southern Methodist University Press, 1968. (JR, pp. 447-448.)

268. González y Contreras, Gilberto. "Las letras mexicanas durante medio siglo". Boletín Bibliográfico de la Secretaria de Hacienda y Crédito Publico, Oct. 10, 1956, p. 3.

269. - "Las letras mexicanas durante medio siglo". Cuadernos, 19 (julio-agosto, 1956), 168-174.

270. Harss, Luis. "JR, Contemporary Mexican Novelist". New Mexico Quarterly, XXXV (1966), 293-318. 
271. —- "JR, o la pena sin nombre", pp. 301-337. En su Los nuestros. Buenos Aires: Editorial Sudamericana, 1966.

272. —, y Barbara Dohmann. "JR, or the Souls of the Departed", Chap. VII, pp. 246-275. En su Into the Mainstream: Conversations with Latin-American Writers. New York: Harper \& Row, 1967.

273. Horányi, Mátyás. "JR, az újitó". Helikon, XV (1969), 432-440.

274. Iglesias, Ignacio. "Novelas y novelistas de hoy". Mundo Nuevo, Núm. 28 (1968), 84-88.

275. Irby, James East. "JR", pp. 132-163. En su "La influencia de William Faulkner en cuatro narradores hispanoamericanos". México: Tesis, Escuela de Verano, UNAM, 1957.

276. Latcham, Ricardo. "Perspectivas de la literatura hispanoamericana contemporánea". Atenea, 380-381 (1958), 305-336.

277. Lavin Cerda, Hernán. "Un Rulfo esquivo y maniatado". Punto Final (dic., 1966).

278. Leal, Luis. Breve bistoria de la literatura bispanoamericana. New York: Alfred A. Knopf, 1971. (JR, pp. 287-288.)

279. - Breve bistoria del cuento mexicano. México: Ediciones de Andrea, 1956. (JR, Pp. 141-142.)

280. —- "Contemporary Mexican Literature: A Mirror of Social Change". The Arizona Quarterly, XVIII, 3 (Autumn, 1962), 197-207.

281. - El cuento bispanoamericano. Buenos Aires: Centro Editor de América Latina, 1967. (JR, p. 49.)

282. - - "Escritores del México actual", La Nueva Democracia (New York), XL (1960), 16-21.

283. - Historia del cuento hispanoamericano. México: Ediciones de Andrea, 1966. (JR, p. 131.)

284. ——. "JR", p. 93. En su Cuentistas bispanoamericanos del siglo veinte, Luis Leal, ed. New York: Random House, 1972.

285. - "JR", p. 155. En su Antologia del cuento mexicano, Luis Leal, ed. México: Ediciones de Andrea, 1957.

286. —_. "La literatura mexicana en el siglc XX, II, 1940-1963". En Panorama das literaturas das Américas, Angola, IV (1965), 1197. 2050.

287. —_. "The Mexican Short Story". Arizona Quarterly, XII (1956), 24-34.

288. - México: Civilizaciones y culturas, revisado. Boston: Houghton Mifflin Co., 1971. (JR, p. 146.)

289. - "The New Mexican Short Story". Studies in Sbort Fiction, VIII, 1 (Winter, 1971), 9-19. 
290. —- "La nueva narrativa mexicana". Nueva Narrativa Hispanoamericana, II, 1 (enero de 1972), 89-97.

291. - Panorama das literaturas das Américas. Tomo IV. Trabajo general de Joaquín de Montezuma de Carvalho. Nova Lisboa, Mozambique: Editado por el Municipio, 1965.

292. - Panorama de la literatura mexicana actual. Washington, D. C.: Unión Panamericana, Secretaría General de la Organización de los Estados Americanos, 1968. (PP, pp. 128-130; LL, pp. 140-142.)

293. - "La protesta social como tema en el cuento mexicano". Revista Mexicana de Cultura, Núm. 871 (diciembre 8, 1963), 1, 4.

294. —- "El realismo mágico en la literatura hispanoamericana". Cuadernos Americanos, CLIII (julio-agosto, 1967), 230-235.

295. —_. "Trends in the Development of the Spanish American Novel". Emory University Quarterly, No. 13 (1957), 27-34.

296. Leal Cortés, Alfredo. "50 años de literatura mexicana". Mañana, Núm. 840 (oct. 13, 1959), 124-126.

297. Leiva, Raúl. "JR, Premio Nacional de Letras". MC, Núm. 1133 (13 de diciembre, 1970), 3.

298. Loveluck, Juan. "Introducción: Crisis y renovación de la novela hispanoamericana", pp. 11-29. En La novela hispanoamericana, Juan Loveluck, ed. Tercera edición actualizada. Santiago, Chile: Editorial Universitaria, 1969.

299. - "Notas sobre la novela hispanoamericana actual". Hispania XLVIII (1965), 220-225.

300. - - ed. La novela bispanoamericana. Selección, introducción y notas dé Juan Loveluck. Tercera edición actualizada. Santiago, Chile: Editorial Universitaria, Colección Letras de América, Vol. 21, 1969.

301. - "Perspectivas de la literatura hispanoamericana contemporánea", pp. 375-406. En La novela bispamoamericana. Santiago, Chile: Editorial Universitaria, s. f., c. 1960 . (JR, p. 382.)

302. - "Una revisión de la novela hispanoamericana". Atenea, Núm. 163 (1966), 139-148.

303. Luna, Norman Joseph. "In the Land of Xipec Totec: A Comparative Study of the Experimental Novels of Agustín Yáñez, Carlos Fuentes, and Juan Rulfo". Boulder: University of Colorado, tesis doctoral inédita, 1969.

304. - - "In the Land of Xipec Totec: A Comparative Study of the Experimental Novels of Agustín Yáñez, Carlos Fuentes, and Juan 
Rulfo". Dissertation Abstracts International, XXX (1969), ... 2536A-2537A.

305. Luquín, Eduardo. "La novelística mexicana y una novela". GI, 26 de mayo, 1957, p. 6.

306. Magaña Esquivel, Antonio. "El arte de novelar de JR". Revista Mexicana de Cultura, Suplemento dominical de El Nacional, Núm. 990 (20 de marzo, 1966), 1.

307. Magill, Frank N., ed. "PP", pp. 3537-3539. En Survey of Contemporary Literature, Vol. 5. New York: Salem Press, 1971.

308. Martínez, José Luis. "La literatura", pp. 311-368. En México: Cincuenta Años de Revolución. Vol. IV, La Cultura. México: Fondo de Cultura Económica, 1962.

309. - - "La literatura mexicana actual (1954-1959)". Revista de la Universidad de México, XIV, 4 (dic., 1959), 11-17. (JR, p. 13.)

310. - "Las letras patrias", pp. 335-447. En México y la Cultura. México: Secretaría de Educación Pública, 1961.

311. McMurray, George. "Current Trends in the Mexican Novel". Hispania, LI (1968), 532-537.

312. Menton, Seymoir. El cuento bispanoamericano. Antologia criticobistórica. México: Fondo de Cultura Económica, 1964. (JR, p. 191, T. II; comentario sobre “¿Díles que no me maten!", pp. 199201, T. II.)

313. Meregalli, Franco. Narratori Messicani. Milano, 1957.

314. Miliani, Domingo. La realidad mexicana en su novela de boy. Caracas, Venezuela: Monte Avila Editores, C. A., 1968. (JR, 69 67-71.)

315. Millán, María del Carmen. "Las novelas clásicas mexicanas de los últimos veinticinco años". Revista lberoamericana, XXXV, 69 (1969), 521-529.

316. Miró, Emilio. "JR". Cuadernos Hispanoamericanos, Núm. 246, 600-637.

317. Monguió, Luis. "A Decade of Spanish American Prose Writing". Hispania, XL (1957), 287-289.

318. Monterde, Francisco. "The Mexican Short Story, From the Revolution to the Present". Recent Books in Mexico, II, 3 (1956), 1, 6.

319. Oberhelman, Harley D. "The Absurd in Three Representative Spanish American Novelists". F 31 [sic], 95-110.

320. Olza Zubirí, Jesús. "Novelistas contemporáneos hispanoamericanos". Estudios Centroamericanos (San Salvador), XXI, 219 (1966), 215-218. 
321. O'Neill, Samuel J., Jr. "Psychological-Literary Techniques in Representative Contemporary Novels of Mexico". College Park, Maryland: University of Maryland. Tesis doctoral inédita, 1965. (PP, pp. 265-333.)

322. Ospina, Uriel. Problemas y perspectivas de la novela americana. Bogotá, 1964.

323. Pagés Larraya, Antonio. "Tradición y renovación en la novela hispanoamericana". Mundo Nuevo, Núm. 34 (1969), 76-82.

324. Passafari, Clara. "Apuntes para una comprensión de la novela mexicana actual". Universidad (Santa Fe, Argentina), Núm. 68 (1966), 267-296.

325. - Los cambios en la concepción y estructura de la narrativa mexicana desde 1947. Rosario, Argentina: Facultad de Filosofía y Letras de la Universidad Nacional del Litoral, 1968.

326. Pla. Josefina. "En torno al libro 'El arte de JR'". Revista Mexicaria de Cultura, mayo 14, 1966.

327. Prenz, Juan Octavio. "La temática de la novela hispanoamericana". Filoski Pregled (Belgrado), No. 3-4 (1964), 89-101.

328. Pupo-Walker, Enrique. "La transposición de valores pictóricos en la narrativa de Ferretis y. Rulfo". Nueva Narrativa Hispanoamericana, I, 1 (enero de 1971), 95-103.

329. Rabell, Malkah. "Rulfo: Una obra solitaria y única". El Día, jueves, 26 de noviembre de 1970, p. 10.

330. Rama, Angel. "Diez problemas para el novelista latinoamericano". Casa de las Américas, IV, 26 (octubre-noviembre, 1964), 3-43.

331. - . "Diez problemas para el novelista latinoamericano", pp. 277-336. En La novela hispanoamericana, Juan Loveluck, ed. Tercera edición actualizada. Santiago, Chile: Editorial Universitaria, 1969.

332. - "Fantasmas, delirios y alucinaciones", pp. 39-55. En Actual narrativa latinoamericana. Copilación del Centro de Investigaciones Literarias. Habana: Casa de las Américas, 1969. (Seguido de mesa redonda, pp. 55-69, con Rubén Bareiro, Noé Jitrik, Salvador Garmendia y Angel Rama.)

333. Rebetez, René. "Número 7: Lo fantástico en la literatura mexicana: Juan Rulfo-Salvador Elizondo". El Heraldo Cultural, Núm. 273 (domingo, 31 de enero de 1971), 4-5.

334. Recopilación de textos sobre Juan Rulfo. Serie Valoración Múltiple. La Habana: Casa de las Américas, Centro de Investigaciones Literarias, 1969. (Con artículos de Luis Harss, Arturo 
Melgoza, Elena Poniatowska, José de la Colina, Belkis Cuza Malé, Reinaldo Arenas, Antonio Benítez Rojo, Hugo Rodríguez Alcalá, Mariana Frenk, Luis Leal, Alí Chumacero, Ricardo Estrada, Emmanuel Carballo, Claude Couffon, María Teresa Gómez Gleason.)

335. Reyes Nevares, Salvador. "Papel y tinta". Reseña de La Cordillera, novela por aparecer de JR. CM, Núm. 104 (12 de feb., 1964), XIX.

336. Roa Bastos, Augusto. "Imagen y perspectiva de la literatura actual". Universidad (Universidad de El Salvador), Núm. 1 (1968), 8-17.

337. —. "La narrativa latinoamericana actual". Temas (Montevideo), Núm. 2 (1965), 3-12.

338. Rodman, Selden. Mexican Joumal: T'he Conquerors Conquered. New York: Devin-Adair Co., 1958.

339. Rodríguez Alcalá, Hugo. El arte de Juan Rulfo: Historias de vivos y difuntos. México: Ediciones de Bellas Artes, 1965.

340. —. "JR: Nostalgia del Paraíso". Nueva Narrativa Hispanoamericana, II, 2 (sept. de 1972), 65-75.

341. Rodríguez Monegal, Emir. "The New Novelties" [sic]. Encounter (London), XXV, 3 (sept., 1965), 97-109.

342. —. "La nueva novela en Latinoamérica". Life en Español, XXV, 6 (15 de marzo, 1965).

343. —_. "La nueva novela latinoamericana", pp. 337-355. En La novela bispanoamericana, Juan Loveluck, ed. Tercera edición actualizada. Santiago, Chile: Editorial Universitaria, 1969. (JR, pp. 351-355.)

344. - "Los nuevos novelistas", pp. 33-41. In La novela iberoamericana contemporánea: XIII Congreso Internacional de Literatura Iberoamericana. Segunda Reunión, 2 al 13 de agosto de 1968. Caracas, Venezuela: Ediciones de OBE (Organización de Bienestar Estudiantil), Universidad Central de Venezuela, 1968.

345. Romero, Graciela. "Nuevos descubridores de América; Novelistas desterrados". Excelsior, domingo, 15 de diciembre, 1968, p. 6-A.

346. Rosaldo, Renato. "A Decade of Mexican Literature: 1950-1960". Arizona Quarterly, XVI, 4 (1960), 319-331.

347. - "A General Survey of the Contemporary Novel in Mexico". Arizona Quarterly, XI, 2 (Summer, 1955), 101-116.

348. Rosson, Mary Ada. "Elements of Mexican Fatalism in JR's Works". Austin, Texas: Tesis inédita, The University of Texas, 1965. 
349. S., A. "Ayuquila, Dionisio Arias, una casta condenada: La cordillera". La Gaceta (del Fondo de Cultura Económica), supl. inúm. 11, 1er. trim., 1964, 7.

350. Sábato, Ernesto. "Realidad y realismo en la literatura de nuestro tiempo". Cuadernos Hispanoamericanos, Núm. 178 (1964), 5-20.

351. Sainz, Gustavo. "Ios 25 mejores cuentos mexicanos, selección y notas de...". MC, Núm. 695 (8 de julio, 1962), 1, 9. (Introducción, p. 1.)

352. Salazar Mallén, Rubén. "Siglo y medio de la novela mexicana: boceto de un ensayo". Mañana, Núm. 892 (oct. 1, 1960), 204205.

353. Sánchez, Porfirio. "La dimensión estético-temática y la novelística de Juan Rulfo y Tomás Mojarro". Cuademos Americanos, Año XXX, Vol. CLXXV, Núm. 2 (marzo-abril, 1971), 197-216.

354. Schneider, Luis Mario. La literatura mexicana, Vol. II. Buenos Aires: Centro Editor de América Latina, 1967. (JR, pp. 33-34.)

355. - "PP en la novela mexicana: ubicación y bosquejo", pp. 121144. En La novela bispanoamericana actual: compilación de ensayos criticos, Angel Flores y Raúl Silva Cáceres, eds. New York: Las Américas, 1971.

356. Schulman, Ivan A. "La novela hispanoamericana y la nueva técnica". Universidad de Antioquia, Núm. 171 (1968), 75-94.

357. Schulman, Ivan A., et al [Manuel Pedro González, Juan Lovèluck y Fernando Alegria]. Coloquio sobre la novela bispanoamericana. México: Tezontle, Fondo de Cultura Económica, 1967.

358. Schwartz, Kessel. A New History of Spanish American Fiction, Vol. II. Social Concern, Universalism, and the New World. Coral Gables, Florida: University of Miami Press, 1972. (JR, pp. 289. 292.)

359. Sommers, Joseph. JR, "Through the Window of the Grave: Juan Rulfo", Chap. III, pp. 69-94. En su After the Storm: Landmarks of the Modern Mexican Novel. Albuquerque, New Mexico: University of New Mexico Press, 1968.

360. - - Yáñez, Rulfo, Fuentes; La novela mexicana moderna: Ensayo. Caracas: Monte Avila, 1970. (JR, pp. 93-121; pp. 221-231; y pp. 235-236.)

361. Soriano, Elena. "Tres escritores de un mundo". Indice, XVIII, Núm. 196 (mayo, 1965), 22-24.

362. Sousa, Raymond. "Language vs. Structure in the Contemporary Spanish American Novel". Hisparia, LII (1969), 833-839. 
363. Torres-Rioseco, Arturo. "El arte de JR". Revista Mexicana de Cultura, Núm. 992 (3 de abril, 1966), 7.

364. - - "Spanish-American Novelists of Today", pp. 72-90. En su Aspects of Spanish-American Literature. Seattle: University of Washington Press, 1963. (JR, pp. 83-84.)

365. —- "Notas sobre el desarrollo de la literatura hispanoamericana desde 1916". Hispania, L (1967), 955-962.

366. - "Novelistas contemporáneos de América". Papeles de Son Armadans, XXVIII, 83 (1963), 125-144.

367. Torre, Guillermo de. "Para una polémica sobre la nueva novela". Mundo Nuevo, Núm. 34 (1969), 83-85.

368. Torriente, Loló de la. "JR y el arte de narrar". El Mundo (La Habana), sábado, 9 de mayo, 1964, p. 4.

369. Traba, Marta. "Crónica de México". Revista Eco (Bogotá, Colombia), 1965.

370. Undarraga, Antonio de. "Crisis en la novela latinoamericana". Cusdernos (París), Núm. 80 (1963), 62-65.

371. Valadés, Edmundo. "El cuento mexicano reciente". Armas y Letras (Revista de la Universidad de Nuevo León), III 4 (octubrediciembre, 1960), 19-39.

372. Valbuena Briones, Angel. "Una cala en el realismo mágico". Cusdernos Americanos, Núm. 166 (1969), 233-241.

373. Valenzuela Rodarte, Alberto. "Nuevos ingenios mexicanos". Abside, XXII (enero-marzo, 1958), 81-100.

374. Vázquez A., José. "A Literary Letter from Mexico". The New York Times Book Review, Sept. 16, 1956, p. 45.

375. Vela, Arqueles. Fundamentos de la literatura mexicana. Segunda edición. México: Editorial Patria, 1966. (JR, pp. 156-157.)

376. Vélez, Joseph Francisco. "El tema de la muerte en la novela contemporánea mexicana". Norman, Oklahoma: The University of Oklahoma, tesis doctoral inédita, 1969.

377. Verdugo, Iber H. "Perspectivas de la actual novela hispanoamericana". Mundo Nuevo, Núm. 28 (1968), 75-83.

378. Von Hanffstengel, Renate. "El México de hoy en la novela y el cuento". México: Tesis, UNAM, Escuela de Verano y Cursos Temporales, 1966.

379. Washburn, Yulan M. "Cosmopolitanismo in the Contemporary Mexican Short Story". Chapel Hill: University of North Carolina, tesis doctoral inédita, 1967. 
380. Xirau, Ramón. "JR, nuevo escritor de México". Insula, XVI, 179 (oct., 1961), 4.

381. - "Mexicanism: The Theory and the Reality". Texas Quarterly, II, 1 (Spring, 959), 22-35.

382. - "Variety and Contrast: The New Literature". Traducción de Juan M. Alonso. Atlantic, CCXIII (March, 1964), 142-145.

383. X. Y. Z. "Rulfo por carambola... Los escritores mexicanos se avergüenzan de sus influencias". MC, Núm. 684 (22 de abril, 1962), 2.

384. Yáñez, Agustín. [Discurso en la ceremonia del Premio Nacional de Letras 1970.] El Día, jueves, 26 de noviembre, 1970, p. 10.

385. Zendejas, Francisco. "Carta a los intelectuales de México". Revista de América, 31 de julio, 1955, pp. 11-13, 48. (JR, p. 12.)

VII. Reseñas y artículos sobre El llano en llamas

386. [A.R.S.] Reseña de El llano en llamas. Summa. (Guadalajara), 4 (1954), 275-276.

387. Ahmad Khan, Fareed. "Cinco cuentistas mexicanos modernos". México: Tesis, Facultad de Filosofía y Letras, UNAM, 1963. (JR, pp. 97-122.)

388. Alvarez Palacios, Fernando. "JR o los silencios de piedra". I. $E l$ Correo de Andalucía (Sevilla), viernes, 31 de julio, 1970, p. 16.

389. Anon. "Aguja de diversos". CM, Núm. 328 (29 de mayo, 1968), XIII.

390. —- Reseña de la 5a. edición de LL. La Gaceta del Fondo de Cultura Económica, XI, 116 (abril, 1964), 8.

391. - - Reseña de The Burning Plain. Booklist, Vol. 64 (June 1, 1968), 1128.

392. — - Reseña de The Burning Plain. Cboice, Vol. 5 (Sept., 1968), 783.

393. Brotherston, Gordon, and Mario Vargas Llosa, ed. Seven Stories from Spanish America. New York: Pergamon Press, 1968. (JR, p. 33.)

394. Congrains Martin, Enrique. Antología contemporánea del cuento mexicano. México: Instituto Latinoamericano de Vinculación Cultural, 1963.

395. Coddou, Marcelo. "Fundamentos para la valoración de la obra de 
JR." Nueva Narrativa Hispanoamericana, I, 2 (Septiembre de 1971), 139-158. (Sobre "El hombre.")

396. Couffon, Claude. "El semanario 'Les Lettres Francaises' habla del arte de JR." CM, Núm. 263 (1 de marzo, 1967), XVI.

397. Coulson, Graciela. "Observaciones sobre la visión del mundo en los cuentos de JR." Nueva Narrativa Hispanoamericana, I, 2 (septiempre de 1971), 159-166. (Sobre "Talpa" y "No oyes ladrar los perros.")

398. Durán, Manuel. "JR, cuentista: La verdad casi sospechosa." Nueva Narrativa Hispanoamericana, I, 2 (septiembre de 1971), 167-174. 399. Fernández, Sergio. "LL." Filosofía y Letras, XXVII (enero-junio, 1954), 259-269.

400. Fressard, Jacques. "Cultura Americana en Europa." Reseña de LL. (Originalmente en Quinzaine Litteraire) Excelsior, domingo, enero 22 de 1967, p. 6.

401. Galván Cándido: "A propósito de 'El hombre,' cuento de Rulfo." Et Caétera, IV, 14 (marzo-abril, 1969), 99-104.

402. Goodsell, J. N. "Mexican Miniatures." Reseña de The Burning Plain. Christian Science Monitor. Jan. 4, 1968, p. 11.

403. Gordon, Donald K. "JR: cuentista." Cuadernos Americanos, 155, 6 (nov.-dic., 1967), 198-205. (Concentra sobre "El hombre".) 404. Hernández, Julia. Novelistas y cuentistas de la Revolución. México: Uinidad Mexicana de Escritores, 1960. (JR, p. 285.)

405. Hill, Diane E. "Integración, desintegración e intensificación en los cuentos de JR." Revista Iberoamericana, XXXIV, 66 (julio-dic. de 1968), 331-338.

406. Huish, L. R. Reseña de The Burning Plain. Library Joumal, XCIII (March 15, 1968), 1145.

407. - - Reseña de The Burning Plain, p. 360. En The Library Journal Book Review 1968. New York: R. R. Bowker Co., 1969.

408. Kooreman, Thomas E. "Estructura y realidad en LL." Revista Iberoamericana, XXXVIII, 79 (abril-junio de 1972), 301-305.

409. Leal, Luis. "El cuento de ambiente: 'Luvina' de JR." Nivel, Núm. 38 (25 de febrero, 1962), 4.

410. Leonard, 1. A. "Banditry and Bedding on Bedrock." Reseña de The Burning Plain. Saturday Review, LI (June 22, 1968), 66.

411. Melgoza, Arturo. "El cuento y el cuentista." El Cuento (junio, 1968), 252-254.

412. Oberhelman, Harley D. "A Forgotten Text of JR." Hispania, LV, 1 (March, 1972), 167-168. (Sobre "Un pedazo de noche.") 
413. Paschero, Celia. Reseña de LL. Ficción (Buenos Aires), Núm. 38 (1962), 87-88.

414. Robbins, Stephanie M. "Yuxtaposición como técnica en un cuento de JR: 'Macario.'" Insuld, XXV (Sept.), 10.

415. Rodríguez Alcalá, Hugo. "Análisis estilístico de LL." Cuademos Americanos, XXIV, 3 (mayo-junio, 1965), 211-234.

416. __. "En torno a un cuento de JR: 'No oyes ladrar los perros." " Papeles de Son Armadans, XLI (mayo, 1966), 135-150.

417. —. "Estudio estilístico de 'En la madrugada' de JR." Hispanic Review, XXXIV (1966), 228-241.

418. —- "Un cuento entre dos luces: 'En la madrugada,' de JR," pp. 499-512. En Actas del Segundo Congreso Internacional de Hispanistas, Sánchez Romeralo, Jaime y Norbert Poulussen, eds.

419. Schade, George D. "Introduction," pp. ix-xiv, En The Burning Plain and Otber Stories de JR, Traducción de George D. Schade. Austin: University of Texas Press, 1967.

420. Server, Alberta Wilson. Reseña de LL. Books Abroad (University of Oklahoma Press), 29, 1 (Winter, 1955), 86.

421. Smith, Gaylord Ewing. "The Short Stories of JR." Austin: Tesis inédita, The University of Texas, 1964.

422.Souto Alabarce, Arturo. Reseña de LL. Ideas de México, IV, 4 (marzo-abril, 1954), 182-184.

423. Speratti Piñero, Emma Susana. "Un narrador de Jalisco." Reseña de LL. Buenos Aires Literaria, II, 17 (febrero, 1954), 57-59.

424. Torre, Gerardo de Ia. "JR: LL." El Nacional, viernes, 4 de diciembre de 1970, 2a. sección, p. 5.

425. Valadés, Edmundo. "El libro de JR quema las manos." MC, Núm. 245 (29 de noviembre, 1953), 2.

426. Von Munk Benton, Gabriela. "El ambiente tural de LL," pp. 123129. En Literatura Iberoamericana, Influencias locales. Memoria del X Congreso del Instituto Internacional de Literatura Iberoamericana. México, 1965.

427. Zelaya, María Elena. Reseña de LL. Revista Interamericana de Bibliografía, Núm. 3 (1954), 241.

428. Zendejas, Francisco. "Los libros de última hora." Reseña de LL. MC, Núm. 241 (1 de noviembre, 1953), 2.

429. ——. "Yet..." Reseña de la 2nda. edición correjida y aumentada" de LL. Excelsior, viernes, 25 de sept., 1970, p. 27-A. 
VIII. Reseñas y attículos sobre Pedro Páramo

Reseñas, artículos, tesis, capitulos en libros y libros completos que tratan de la novela de Rulfo se encuentran en esta sección.

430. Acuña Salas, Feliciano. Memorias sobre PP. Santiago, Chile: Universidad Católica de Chile, 1970.

431. Alvarez Palacios, Fernando. "JR o los silencios de piedra." (II) El Correo de Andalucia (Sevilla), viernes, 7 de agosto, 1970, p. 20.

432. Anaya-Sarmiento. "PP y JR: Tres pequeñas entrevistas." Revista Mexicana de Cultura, No. 429, 19 de julio, 1955, 4, 10.

433. Anon. "Las dos mejores novelas de 1955." MC, Núm. 356 (15 de enero, 1956), 2.

434. —- "Escaparate." MC, Núm. 1123 (4 de octubre de 1970), 7.

435. —. "The Living and the Dead." Reseña de PP. The Times Literary Supplement, No. 3023 (Feb. 5, 1960), 86.

436. _ـ . "Una nueva edición de la famosa novela PP." Reseña de la 6a. edición de PP. RS, 8 de noviembre, 1964, p. 3.

437. ——. "PP, traducida al eslovaco." El Día, miércoles, 23 de sept. de 1970, p. 15.

438. —- "PP: una vida bajo signos de fatalidad." Visión, 1 de abril, 1966, p. 40. (Reseña de la versión fílmica de PP.)

439. - - Reseña de PP. Kirkus, Vol. 27 (Feb. 15, 1959), 157.

440. —. Reseña de PP. MC, Núm. 575 (20 de marzo, 1960), 11.

441. Arizmendi, Aralia L. "Alrededor de PP." Cuadernos Americanos, Año XXX, Vol. CLXXV, Núm. 2 (marzo-abril, 1971), 184-196.

442. Aymami, Jorge. "PP. en La Habana." El Día, 15 de enero, 1965, p. 9.

443. Bell, Alan S. "Rulfo's PP: A Vision of Hope." Modern Language Notes, LXXXI, 2 (March, 1966), 238-245.

444. Blanco Aguinaga, Carlos. "Las dos mejores novelas de 1955." Novedades, 15 de enero, 1955.

445. Burns, Archibaldo. "PP o la unción y la gallina." MC, Núm. 321 (15 de mayo, 1955), 3.

446. Calleros, Mario. Reseña de PP. Ovaciones, Supl. núm. 125 (17 de mayo, 1964), 7.

447. Carballo, Emmanuel. Reseña de la 6a. Edición de PP. CM, Núm. 147 (9 de diciembre, 1964), XX.

448. Carpeaux, Otto María. "Introdução," pp. 9-12. En PP, traducción 
de Jurema Finamour al portugués. São Paulo: Editora Brasilense, 1969.

449. Chávarri, Raúl. "Una novela en la frontera de la vida y de la muerte." Cuadernos Hispanoamericanos, Nủm. 196 (abril, 1966), 174179.

450. Chumacero. Ali. "El PP de JR." Universidad de México, IX, 8 (abril, 1955), 25-26.

451. Colina, José de 1a. "Susana San Juan, el mito femenino en PP." Unversidad de México, XIX, 8 (abril, 1965), 19-21.

452. Couffon, Claude. "La muerte lleva el juego." 'Traducción de José Emilio Pacheco. Estaciones, IV (invierno, 1959), 494-495.

453. Cruz, Salvador de la. Reseña de PP. Metáfora, Núm. 2 (mayo-junio, 1955), 35-36.

454. Dorfmann, Ariel. "En torno a PP, de JR," pp. 181-192. En su Imaginación y violencia en América. Santiago de Chile: Editora Universitaria, 1970.

455. - "En torno a PP, de JR." Mapocbo, 15, 4 (1966), 289-295.

456. Elizondo, Carlos. "Sobre PP." Hoy (México), Núm. 961 (23 de julio, 1955), 46.

457. Embeita, María J. "Tema y estructura en PP." Cuadernos Americanos, Año XXVI, Vol. CLI, Núm. 2 (marzo-abril, 1967), 218-223.

458. Esteva Fabregat, Claudio. "JR en la novela mexicana." Armas $y$ Letras, XII, 9 (sept., 1955), 1, 7.

459. Estrada, Ricardo. "Los indicios de PP." Universidad de San Carlos (Guatemala), LXV (enero-abril, 1965), 67-85.

460. Fernández de Valle, Dr. Agustín Basave. "PP: Una novela que rezuma esencias mexicanas." El Norte (Monterrey), sábado, 1 de agosto, 1959, p. 2.

461. - Reseña de PP. Armas y Letras, 2, 2, Segunda Epoca (abriljunio, 1959), 84-86.

462. Freeman, George Ronald. "Archetype and Structural Unity: The Fall-From-Grace in Rulfo's PP." Dissertation Abstracts International, XXX (1969), 2537A.

463. —_. "Archetype and Structural Unity: The Fall-from-Grace in Rulfo's PP." Seattle: University of Washington, Ph.D. dissertation, 1969.

464. - Paradise and Fall in Rulfo's PP: Arcbetype and Structural Unity. "Presentation" de Joseph Sommers. CIDOC Cuaderno Núm. 47. Cuernavaca, Morelos: Centro Intercultural de Documentación, 1970. 
465. Frenk, Mariana. "Alemania lee PP." Revista Mexicana de Literatura, Núm. 2 (abril-junio, 1959), 181-185.

466. —_. "PP." Casa de las Américas, II, 13-14 (julio-octubre, 1962), 88-96.

467. ——. "PP." El Escarabajo de Oro, VIII, $34-35$ (julio-agosto y noviembre, 1967).

468. ——. "PP." Universidad de México, XV, 11 (julio, 1961), 18-21.

469. —- "PP inicia en Alemania su viaje por el mundo." MC, Núm. 504 (9 de noviembre, 1958), 7.

470. Fuentes, Carlos. "PP." L'Esprit des Lettres, 6 (nov.-dec., 1955), 74-76.

471. Gibson, Ruby. Reseña de PP. New Mexico Quarterly, III, 1 (1960), 87.

472. Helvig, Werner. "Mexikanischer Orpheus." Stuttgarter Zeitung, Nov. 8, 1958.

473. Henestrosa, Andrés. "La nota cultural." El Nacional, 22 de abril, 1966 , p. 3.

474. Horányi, Mátyás. "La función expresiva de la atmósfera en PP." Acta Litteria Academiae Scientiarum Hungaricate (Budapest), XI (1969), 269-280.

475. Jaén, Didier T. "La estructura lírica de PP." Revista Hispánica Moderna, XXXIII (1967), 224-231.

476. ——. "La evocación lírica en PP." Ided, Artes y Letras (Lima), XVIII, 67-68 (enero-junio, 1967), 1, 11, 12.

477. —_. "El sentido lírico de la evocación del pasado en PP," pp. 83100. En La novela iberoamericana contemporánea: XIII Congreso Internacional de Literatura Iberoamericana, segunda reunión, 2 al 13 de agosto de 1968. Caracas: Universidad Central de Venezuela, Ediciones de OBE (Organización de Bienestar Estudiantil, 1968. 478. Langford, "Walter M. "JR, Novelist of the Dead," Chapter 6, pp. 88-102. En su The Mexican Novel Comes of Age. Notre Dame, Indiana: University of Notre Dame Press, 1971.

479. Leal, Luis. "La estructura de PP." Anuario de Letras, IV (1964), 287-294.

480. —- "Introducción," pp. 105. En PP, Luis Leal, ed. New York: Appleton-Century-Crofts, 1970.

481. Lescot, Roger. Introducción a su traducción al francés de PP por JR. París: Gallimard, 1959.

482. Levine, Suzanne Jill. "PP, Cien años de soledad: un paralelo." Imagen, Núm. 50 (1/15 junio, 1969), 6-8. 
483. Mead, Jr., Robert. "Barren." Carta al New York Times Book Review, August 9, 1959, p. 17.

484. Molina Enríquez, Renato. "Un libro de México." Reseña de PP. Boletín Bibliográfico de la Secretaria de Hacienda y Crédito Público, Núm. 41 (agosto, 1955), 2, 3.

485. Morales de León, Jesús. "Divagaciones sobre PP." Comunidad, II, 9 (oct., 1967), 560-566.

486. Omil, Alba. "PP: El trasmundo y su expresión artística," pp. 145154. En La naturaleza y el hombre en la novela bispanoamericana, Antofagasta, Chile: Universidad del Norte, 1969.

487. Ortega, Julio. "PP." Comunidad Latinoamericana de Escritores (México, D. F.), Boletín Núm. 2 (octubre de 1968), 3-9.

488. - - "PP," pp. 17-30. En su La contemplación y la fiesta: Notas sobre la vovela latinoamericana actual. Caracas, Venezuela: Monte Avila Editores, 1969.

489. Palma, María Marta. "Análisis de PP." Buenos Aires: Tesis de Maestria, Universidad de El Salvador, supervisada por Jorge Bogliano.

490. Peñaloza, Frank, "PP." El Mundo (Caracas, Venezuela), 22 de enero, 1965.

491. Praag, J. A. "JR: PP." Norte (Revista Hispánica de Amsterdam), III, 1. (sept., 1962).

492. Pupo-Walker, C. Enrique. "Personajes y ambiente en PP." Cuadernos Americanos, 28, 167 (nov., 1969), 194-204.

493. - - "Rasgos del lenguaje y estructuras en PP." Papeles de Son Armadans, Año XV, Vol. LVII, Núm. 170 (mayo, 1970), 117 136.

494. R., T. Reseña de PP. San Francisco Chronicle, Aug. 30, 1959, p. 16. 495. Reyes, Alfonso. "Edición francesa de PP." Vida Universitaria (Monterrey, Nuevo León), IX, 429 (junio 10 de 1959), 5.

496. Reyes Nevares, Salvador. "Los libros: PP." Revista Mexicana de Cultura, suplemento de El Nacional, Núm. 424 (15 de mayo de 1955), 12.

497. Robles, Reynaldo. "JR, un nuevo modo de novelar." Cultura (Revista del Ministerio de Educación, San Salvador, El Salvador), Vol. 40 (abril-junio, 1966), 93-96.

498. Rodman, Selden. "PP by JR." New York Times Book Review, LXIV (June 7, 1959), 5, 27.

499. Salazar Mallen, Rubén. "El mensaje en la obra." El Universal, junio 21,1955, p. 3. 
500. Sánchez, Elizabeth Doremus. "The Motif of Descent into Inferno in Los pasos perdidos and PP." Austin: Tesis Inédita, University of Texas, 1969.

501. Schneider, Luis Mario. "PP en la novela mexicana: ubicación y bosquejo," pp. 121-14. En La novela bispanoamericana actual: Compilación de entsayos criticos, Angel Flores y Raúl Silva Cáceres, eds. New York: Las Américas, 1971.

502. Selva, Mauricio de la. "Asteriscos." Reseña de la 6a. edición de PP. DC, 22 de nov., 1964, p. 4.

503. Sepúlveda Llanos, Fidel. "PP" (Análisis estilístico y estético). Seminario-memoria para optar al título de Profesor de castellano. 8 estudios. Facultad de Filosofía y Ciencias de la Educación. Universidad Católica de Chile, 1968.

504. —_. "El ritmo novelesco en PP." Anales (de la Facultad de Filosofía y Ciencias de la Educación de la Universidad Católica de Chile), 1969, pp. 85-102.

505. Sommers, Joseph. "Through the Window of the Grave: JR." New Mexico Quarterly, XXXVIII, 1 (Spring, 1968), 84-101.

506. —- "Through the Window of the Grave: JR," Chapter III, pp. 69-94. En su After the Storm: Landmarks of the Modern Mexican Novel. Albuquerque, New Merico: University of New Mexico Press, 1968.

507. Toral Moreno, Alfonso. "PP." Et Caétera, V, 17-18, 1955, 111-112.

508. Wickenden, Dan. "A Haunting Mexican Novel." Reseña de PP. New York Herald Tribune Book Review, August 2, 1959, p. 5.

509. Wilson Server, Alberta. Reseña de PP. Books Abroad, XXX (Summer, 1956), 323.

510. Xirau, Ramón. "PP, the First Novel of JR." Recent Books in Mexico, I, 4 (May 15, 1955), 3.

511. —_. "Books in Review." Reseña de PP. The News (Mexico City), 24 de mayo, 1959.

512. Zendejas, Francisco. "Donde los sollozos hablan." Reseña de PP. MC, Núm. 318 (24 de abril, 1955), 2, 5.

Addendum

513. Alvarez Z., María Edmés. Literatura mexicana e hispanoamericana. Décima edición. México: Editorial Porrúa, 1970. (JR, pp. 497499.) 
514. Gyurko, Lanin A. "Rulfo's Aesthetic Nihilism: Narrative Antecedents of 'PP'." Hispanic Review, XI, 4 (autumn, 1972), 451-466.

515. Ramirez, Arthur. "Style and Technique in Juan Rulfo." Austin: The University of Texas, tesis doctoral inédita, 1973.

516. Rulfo, Juan. "¡Díles que no me maten!" pp. 110-117. En Los mejores cuentos americanos, Aníbal Quijano, ed. Lima: Baca \& Villanueva, s.f.

517. - - "Luvina," pp. 121-130. En Hispanoamérica mágica y misteriosa: Once relatos. Robert M. Gleaves y Charles M. Vance, eds. New York: Holt, Rinehart \& Winston, 1973. (Nota sobre JR, pp. 118-120.) 
